\title{
Acute administration of Baclofen after spinal cord injury improves locomotor behavior, bladder control and modulates the inflammatory response.
}

\author{
Nídia de Sousa ${ }^{1}$, Andreia Pinho ${ }^{1}$, Susana Monteiro ${ }^{1}$, Valentina Liberato ${ }^{1}$, Diogo Santos ${ }^{1}$, \\ Jonas Campos ${ }^{1}$, Jorge Cibrão ${ }^{1}$, Nuno Silva ${ }^{1}$, Antón Barreiro-Iglesias ${ }^{2}$, and António \\ Salgado $^{1}$ \\ ${ }^{1}$ ICVS 3B's Associate Laboratory \\ ${ }^{2}$ University of Santiago de Compostela Faculty of Biology
}

October 16, 2021

\begin{abstract}
Spinal cord injury (SCI) leads to severe motor and sensory functional impairments that affect personal and social behaviors. With no effective treatment, deficits in motor function are the most visible consequence of SCI. However, other complications produce a significant impact on SCI patient's welfare. Spasticity is a neurological impairment that affects the control of muscle tone as a consequence of an insult in the central nervous system (e.g., SCI). Baclofen, a GABA agonist, is the most effective drug for spasticity treatment. This drug activates GABAB receptors decreasing the neurotransmitters release and neuronal hyperpolarization, which results in spasticity relief. Interestingly, emerging data reveals that Baclofen can also play a role on neuroprotection and regeneration after SCI. Our goal is to highlight the role of Baclofen as a potential treatment to promote recovery from SCI. We used a compression SCI mouse model with the administration of Baclofen at different time-points after injury. Our data showed that Baclofen is more effective when a single dose is administered acutely, leading to locomotor improvements in mice. Moreover, Baclofen administration also led to improved bladder function control in all experimental groups. Interestingly, acute Baclofen administration modulates microglia activation state and levels of circulating cytokines, suggesting a role of Baclofen in the modulation of the immune response. Although deeper studies must be performed to understand the cellular/molecular mechanisms that underlie the functional improvements produced by Baclofen, our data shed light into the pharmacological potential of Baclofen to promote recovery in a SCI context.
\end{abstract}

\section{Hosted file}

DRAFT.docx available at https://authorea.com/users/441387/articles/541900-acuteadministration-of-baclofen-after-spinal-cord-injury-improves-locomotor-behavior-bladdercontrol-and-modulates-the-inflammatory-response 

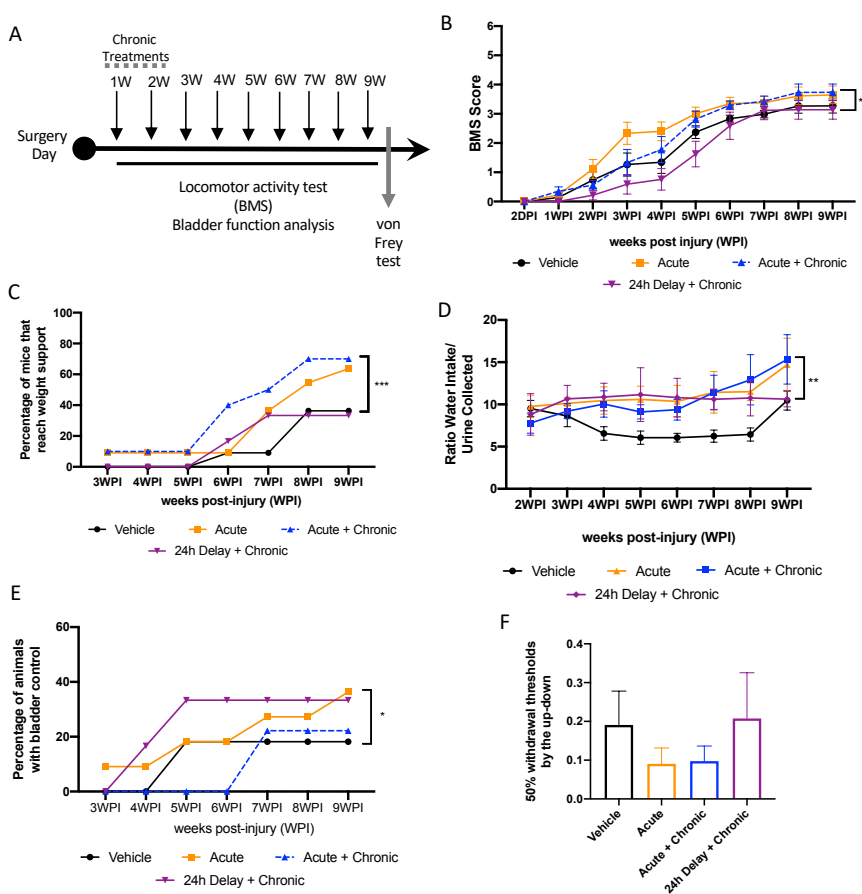

F

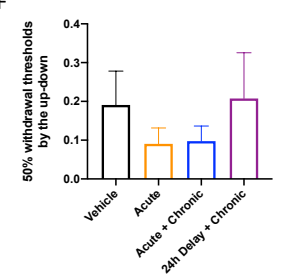



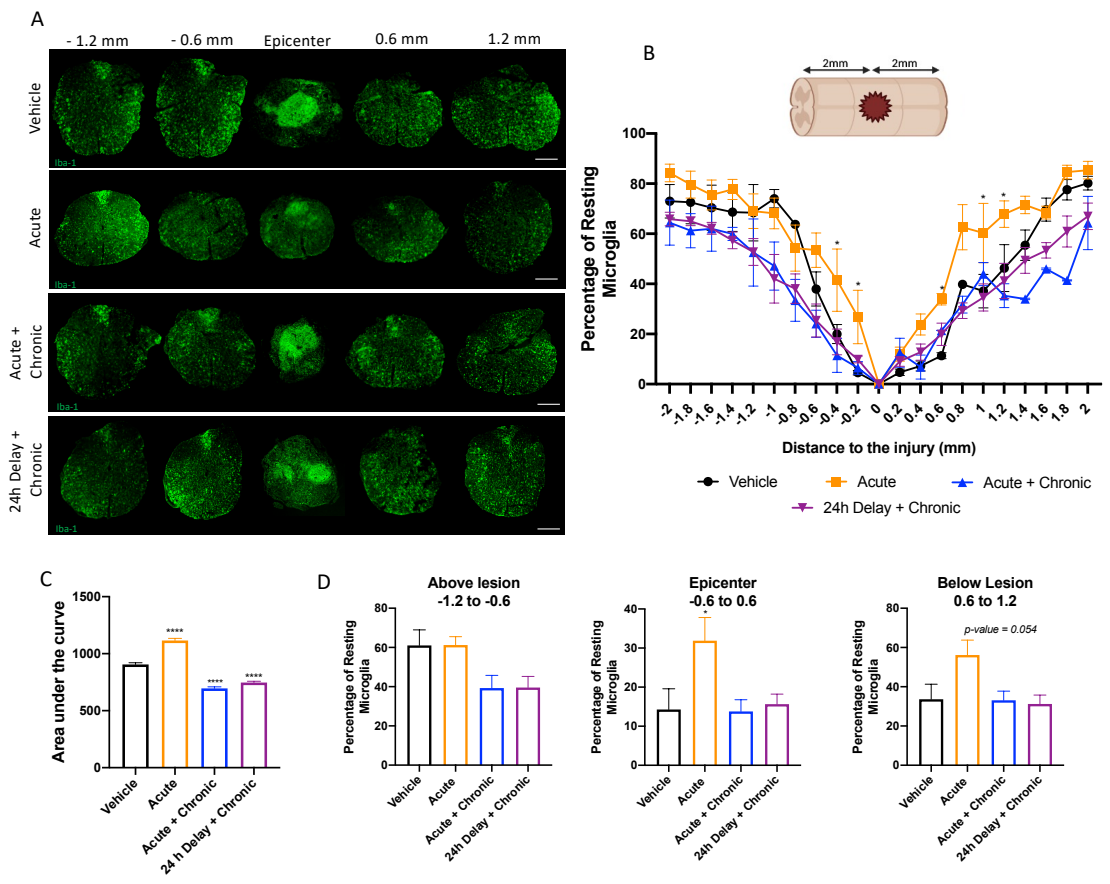


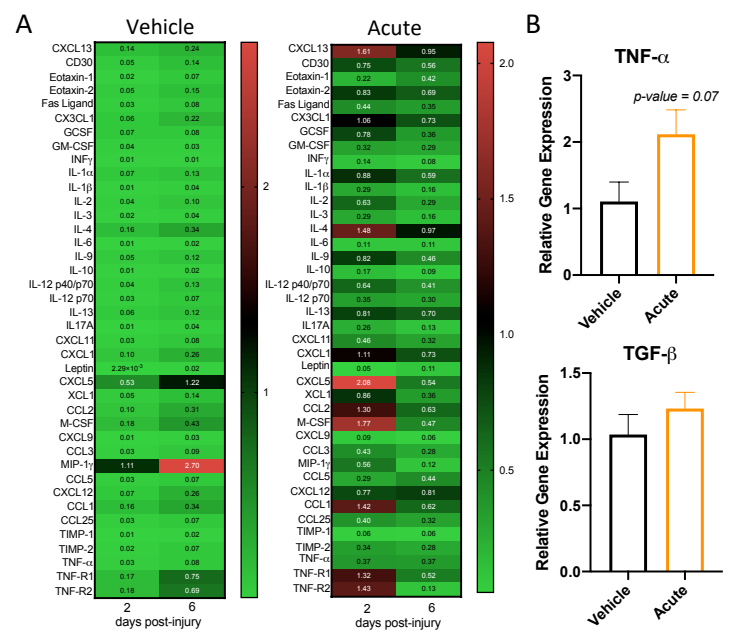




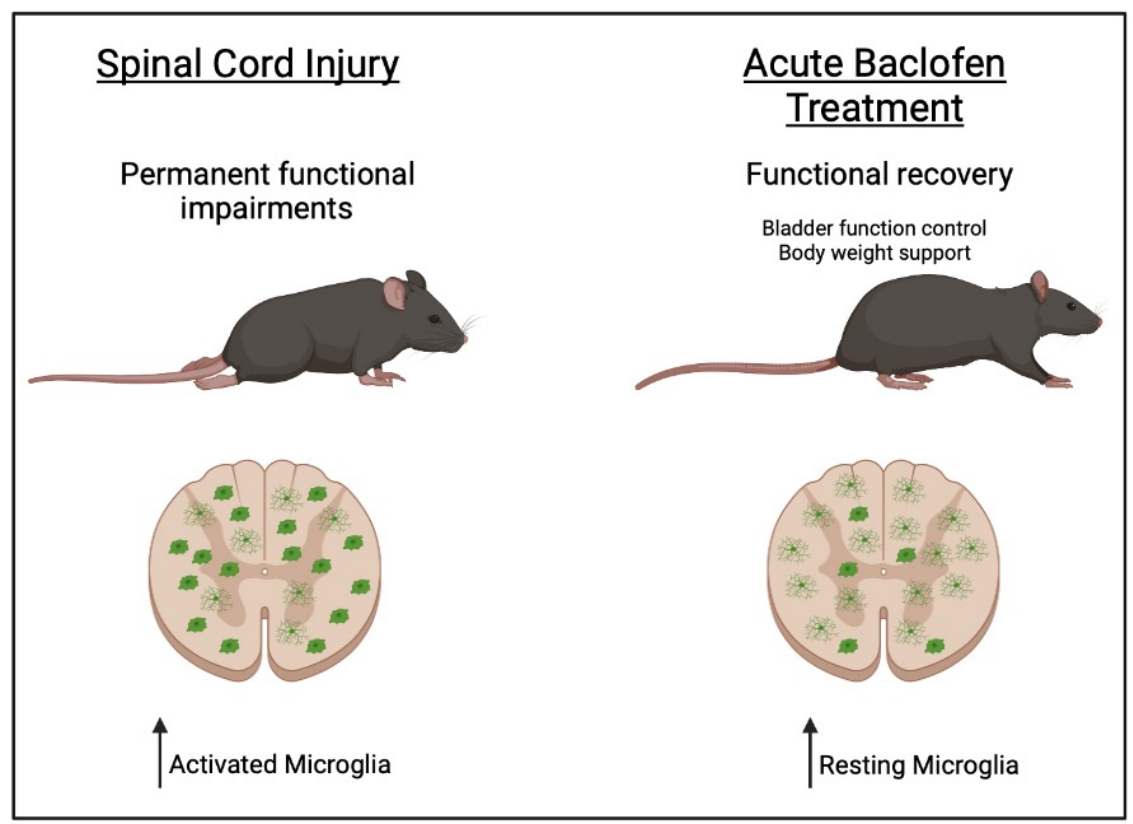

Activated Microglia

Resting Microglia 
A

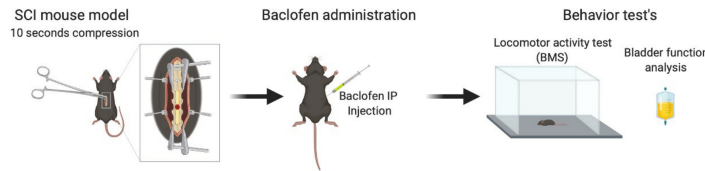

B

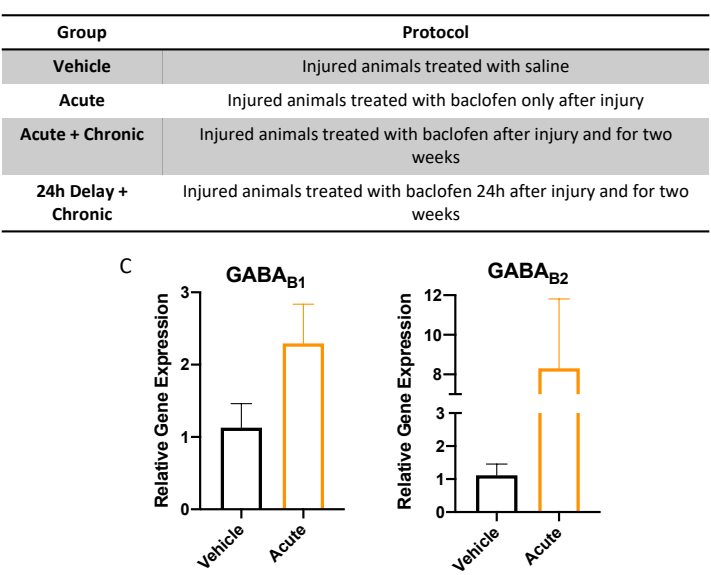



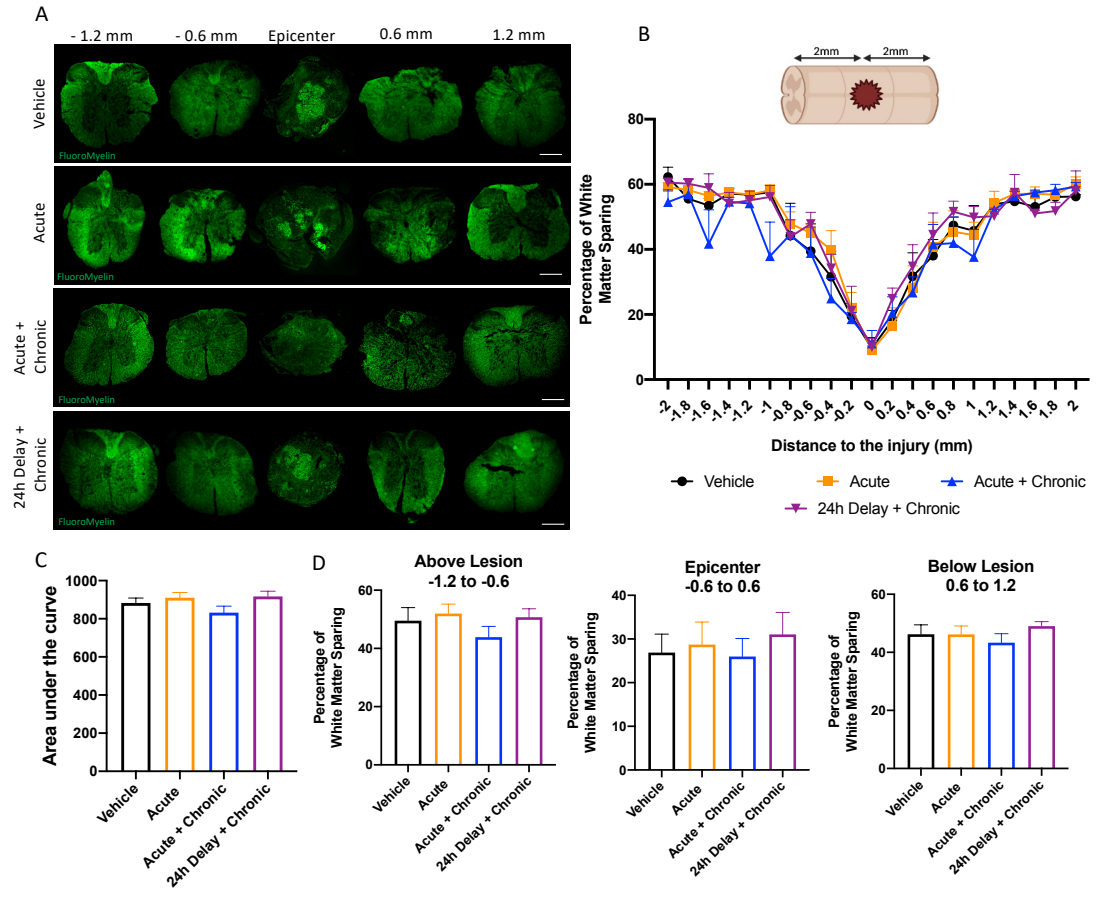


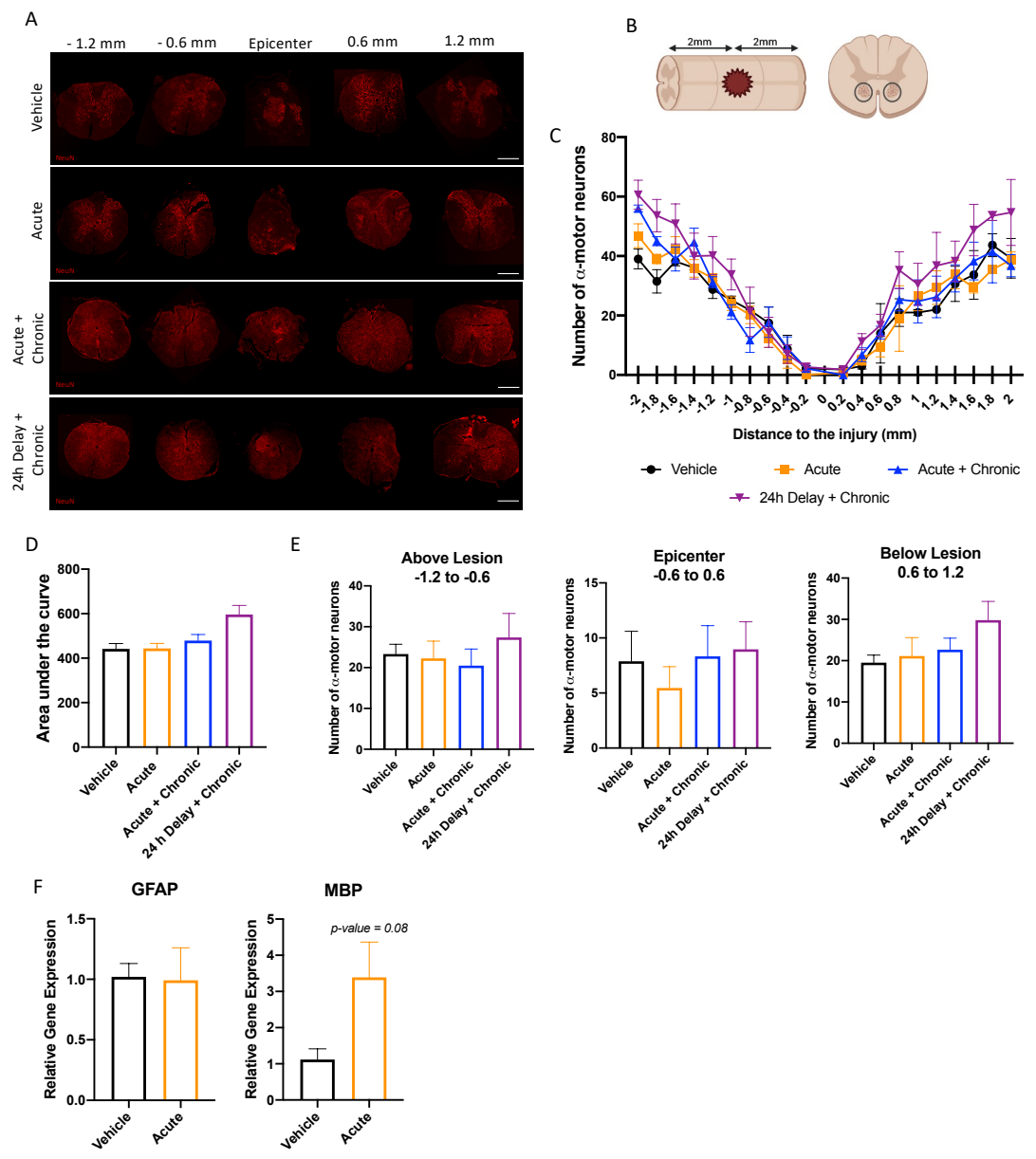




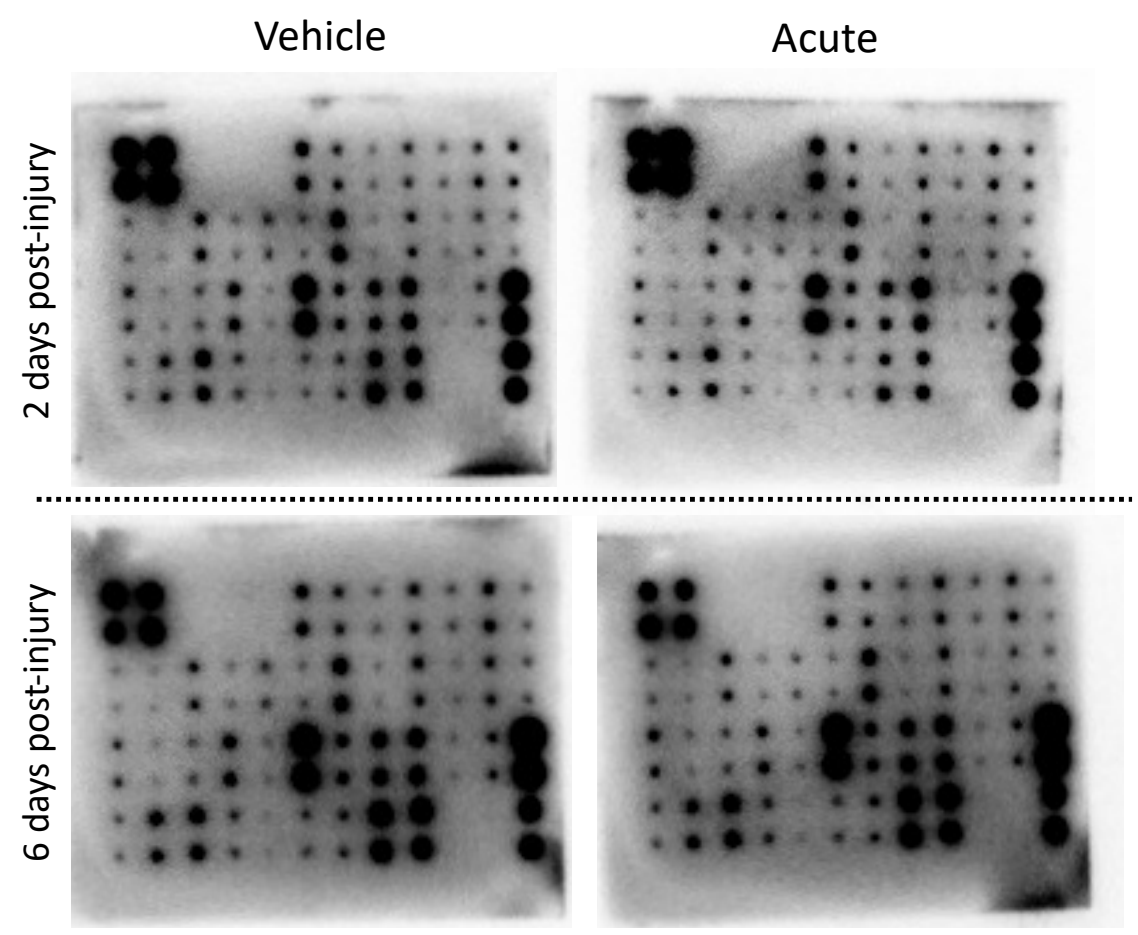

